\title{
Polymer-Supported Benzotriazoles as Catalysts in the Synthesis of Tetrahydroquinolines by Condensation of Aldehydes with Aromatic Amines
}

\author{
Sanjay Talukdar, Rong-Jiunn Chen, Chao-Tsen Chen, Lee-Chiang Lo, and \\ Jim-Min Fang* \\ Department of Chemistry, National Taiwan University, Taipei, 106, Taiwan, Republic of China
}

Received March 20, 2000

\begin{abstract}
Four polymer-supported benzotriazoles were prepared by linkage of 5-(hydroxymethyl)benzotriazole and benzotrizaole-5-carboxylic acid with Wang resin, Merrifield resin, and (monomethoxy)poly(ethylene glycol). The solid-phase and liquid-phase syntheses of tetrahydroquinolines were achieved by two-pair coupling reactions of aldehydes and aromatic amines using these polymer-supported benzotriazoles as the promoters. The ether-type benzotriazole prepared by loading 5-(hydroxymethyl)benzotriazole onto Merrifield resin turned out to be the catalyst of choice. Thus, a series of tetrahydroquinoline products were obtained in high purity by simple filtration, and the resin was recovered for reuse without loss of activity.
\end{abstract}

\section{Introduction}

Combinatorial chemistry ${ }^{1}$ using polymer-bound reagents and catalysts ${ }^{2}$ to build small-molecule libraries has become an efficient tool for accelerating the drug discovery process. Tetrahydroquinolines (THQs) belong to an important heterocyclic system of medicinal and industrial interests. ${ }^{3}$ Many general methods for the synthesis of THQs in solution phase have been developed. ${ }^{3,4}$ A solid-phase synthesis of THQs has been carried out by using a condensation reaction of three components that include benzaldehyde, aniline, and an alkene..$^{5 \mathrm{a}-\mathrm{c}}$ Since one of the reagents is immobilized on a solid support, an additional step is required for cleavage of the THQ product from the polymeric support. On the other hand, strategies that allow automatic release of polymeric support for recycle in the desired transformations are attractive. In the synthesis of THQs, such a strategy has been applied by using polymer-supported microencapsuled scandium triflate as the catalyst..$^{5 \mathrm{~d}}$

We have recently reported a one-pot synthesis of THQs using a two-pair coupling reaction of phenylacetaldehydes and aromatic amines by the promotion of $1 H$-benzotriazole (BtH). ${ }^{6}$ This synthesis involves the initial formation of $N-(\alpha-$ aminoalkyl)benzotriazole from which the $N$-aryliminium ion is generated, and the $\mathrm{Bt}^{-}$counteranion promotes isomerization to give the corresponding enamine. Coupling of the $\mathrm{N}$-aryliminium ion and enamine intermediates thus affords the THQ products. BtH plays both roles as nucleophile and general base in this reaction sequence. ${ }^{7}$ Such tandem reactions, occurring under mild conditions, offer great potential for combinatorial synthesis on structurally defined templates. Indeed, polymer-bound benzotriazoles have recently been developed to generate a library of amines. ${ }^{8} \mathrm{We}$ demonstrate herein the use of polymer-supported benzotriazoles as catalysts for the generation of a THQ library.

\footnotetext{
* To whom correspondence should be addressed. E-mail: jmfang@ mail.ch.ntu.edu.tw.
}

\section{Results and Discussion}

Preparation of Polymer-Supported Benzotriazoles P1P4 (Scheme 1). Benzotriazole-5-carboxylic acid (4) was subjected to esterification, $\mathrm{NH}$ protection, and reduction to give alcohol 5. ${ }^{8 c}$ The corresponding benzyl ether of $\mathbf{5}$ was prepared, and the trityl group was removed to give 5-(benzyloxymethyl)benzotriazole $\mathbf{6}$. On the other hand, alcohol 5 was treated with $\mathrm{CBr}_{4}$ and $\mathrm{Ph}_{3} \mathrm{P}$ to afford the corresponding bromide 7. Bromination of $\mathrm{N}$-trityl-5-methylbenzotriazole also provided compound $\mathbf{7}$ in an efficient manner.

Treatment of acid 4 with $\mathrm{SOCl}_{2}$ gave the corresponding acid chloride, which could be anchored onto Wang resin to give $\mathbf{P 1}$ with a loading of $0.33 \mathrm{mmol} / \mathrm{g}$ on the basis of elemental analyses of nitrogen content. The polymer-bound benzotriazole $\mathbf{P 2}$ was similarly prepared by linkage of the acid chloride with (monomethoxy)poly(ethylene glycol) (MeO-PEG-OH, average molecular weight of $~ 5000$ ). The IR absorptions at 3452 and $1722 \mathrm{~cm}^{-1}$ were attributable to the $\mathrm{NH}$ and ester functionalities. By use of 1-(3-dimethylaminopropyl)-3-ethylcarbodiimide (EDC) as the dehydrating agent, a direct coupling of acid $\mathbf{4}$ with $\mathrm{MeO}-\mathrm{PEG}-\mathrm{OH}$ in the presence of $\mathrm{Et}_{3} \mathrm{~N} / \mathrm{DMPA}$ was less effective to give $\mathbf{P 2}$. The ${ }^{1} \mathrm{H}$ NMR spectrum of $\mathbf{P 2}$ in DMSO- $d_{6}$ showed the signals at $\delta 4.21\left(2 \mathrm{H}\right.$, br s, $\left.\mathrm{MeOCH}_{2}\right)$ and $4.56\left(2 \mathrm{H}\right.$, br s, $\mathrm{BtCO}_{2}-$ $\mathrm{CH}_{2}$ ), in addition to three aromatic protons.

According to the known procedure, ${ }^{8 c}$ alcohol $\mathbf{5}$ was treated with $\mathrm{NaH}$ and reacted with Merrifield resin to give the ethertype resin $\mathbf{P} 3$ after removal of the trityl group. The loading was estimated to be $0.83-0.97 \mathrm{mmol} / \mathrm{g}$ on the basis of nitrogen content. The PEG-bound benzotriazole P4 was prepared by linkage of bromide 7 with the sodium salt of monomethoxy-PEG-OH $\mathrm{OH}_{5000}$, followed by removal of the trityl group. The diagnostic $\mathrm{BtCH}_{2} \mathrm{O}$ group of $\mathbf{P 4}$ appeared at $\delta$ $4.63(2 \mathrm{H}, \mathrm{br} \mathrm{s})$ in the ${ }^{1} \mathrm{H}$ NMR spectrum. The loading of benzotriazole moieties in the PEG-bound benzotriazoles P2 and $\mathbf{P 4}$ was rather low $(\leq 0.15 \mathrm{mmol} / \mathrm{g})$. 


\section{Scheme 1}
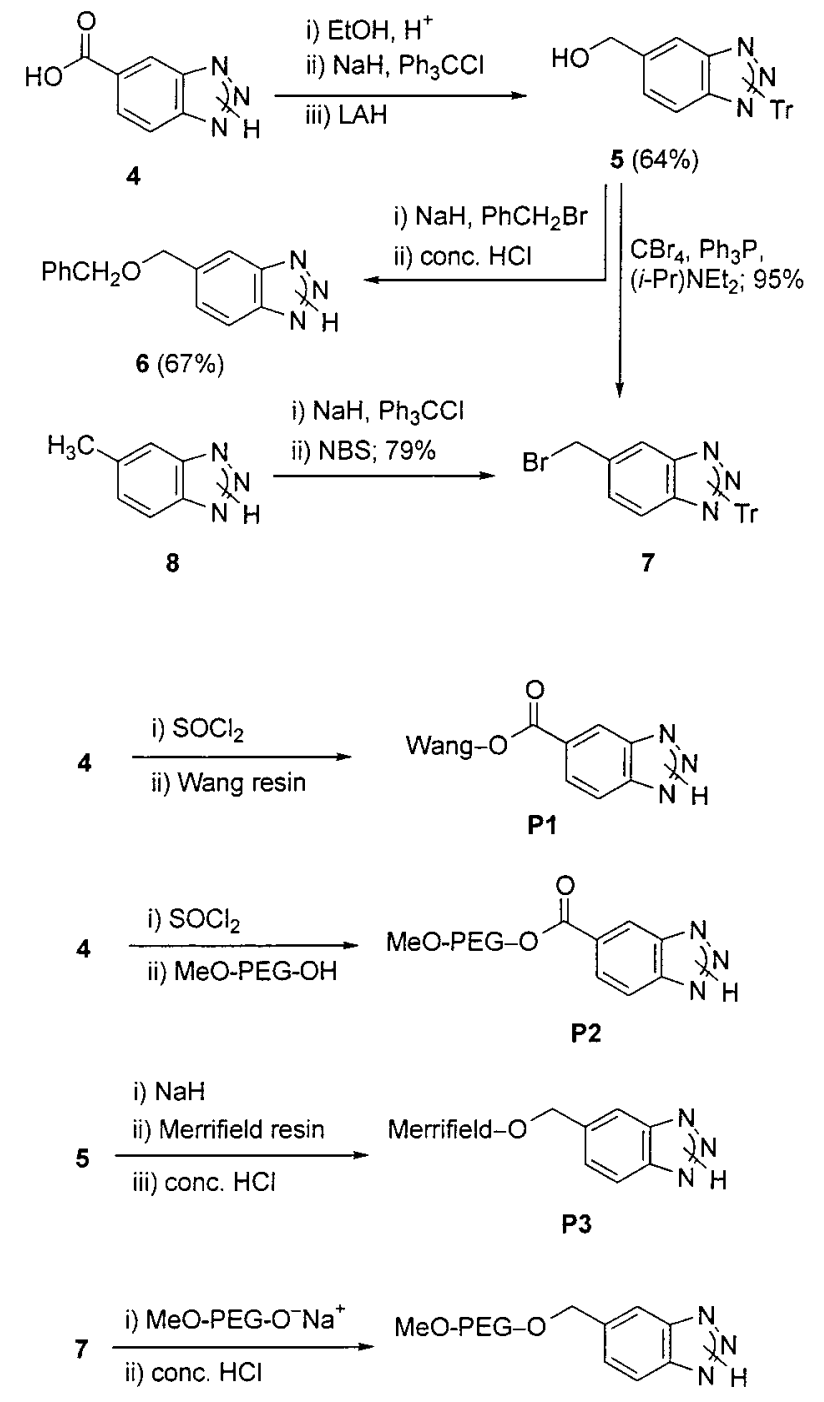

P4

The ester functionality at the 5-positions of $\mathbf{P 1}$ and $\mathbf{P 2}$ would impart a small inductive effect $(-\mathrm{I})$, and the acidity of $\mathbf{P 1}$ and $\mathbf{P} 2$ might slightly increase by comparison with the parent $\mathrm{BtH}\left(\mathrm{p} K_{\mathrm{a}}\right.$ of $\left.\sim 8.2\right){ }^{7}$ On the other hand, the electron-donating alkyl groups at the 5-positions of $\mathbf{P 3}$ and P4 would somewhat intensify the nucleophilicity of benzotriazole. Thus, the polymer-bound benzotriazoles P1-P4 would still meet the electronic requirements of BtH itself to serve as the suitable catalysts in the two-pair coupling reactions for the synthesis of THQs. The PEG-bound benzotriazoles $\mathbf{P} \mathbf{2}$ and $\mathbf{P} \mathbf{4}$ could be used as soluble polymeric matrices in the liquid-phase combinatorial synthesis. ${ }^{9}$ When $\mathbf{P 2}$ and $\mathbf{P 4}$ are used, the progress of reactions could be monitored by TLC and NMR analyses.

Synthesis of Tetrahydroquinolines Using PolymerBound Benzotriazoles as Catalysts (Scheme 2). We chose the facile two-pair coupling reaction of 3-methoxyaniline (1c) and phenylacetaldehyde (2a) as a model to test the viability and efficacy of the polymer-supported benzotriazoles P1P4 (Table 1). For comparisons, the reactions using ethyl benzotriazole-5-carboxylate (4a) and 5-(benzyloxymethyl)benzotriazole (6) as surrogates were also investigated (entries 2 and 3 in Table 1). When the ester-type benzotriazole $\mathbf{4 a}$
Scheme 2

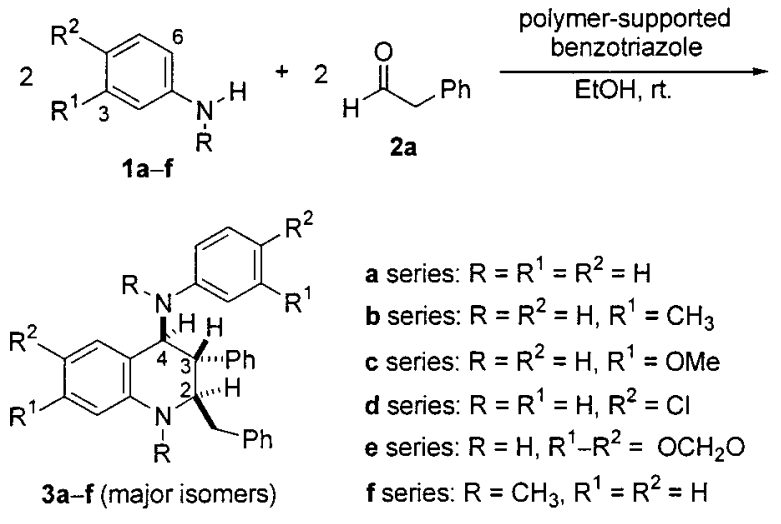<smiles>COc1cccc(N[C@H]2c3ccc(OC)cc3NC(C[14CH3])[C@@H]2C#N)c1</smiles>

$3 g$

$$
3 \mathbf{i}\left(\mathrm{Ar}=0-\mathrm{BrC}_{6} \mathrm{H}_{4}\right)
$$

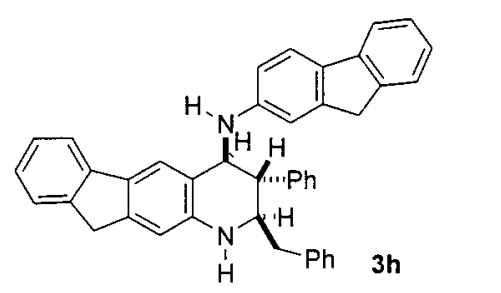

Table 1. Condensation of 3-Methoxyaniline (1c) and Phenylacetaldehyde (2a) Using Various Benzotriazole Derivatives as Promoters To Give Tetrahydroquinoline $\mathbf{3} \mathbf{c}^{a}$

\begin{tabular}{clccc}
\hline entry & $\begin{array}{c}\text { promoter } \\
(\text { mol \%) }\end{array}$ & $\begin{array}{c}\text { reaction } \\
\text { time }(\mathrm{h})\end{array}$ & $\begin{array}{c}\text { yield }^{b} \\
(\%)\end{array}$ & $\begin{array}{c}\text { ratio of } \\
\text { isomers }^{c}\end{array}$ \\
\hline 1 & BtH $(20)^{d}$ & 1 & 78 & $95: 5$ \\
2 & $\mathbf{4 a}^{d}(20)$ & 8 & 74 & $73: 27$ \\
3 & $\mathbf{6}(20)^{2}(20)^{e}$ & 1 & 90 & $97: 3$ \\
4 & $\mathbf{P 1}(10)^{f}$ & 6 & 64 & $95: 5$ \\
5 & $\mathbf{P 2}(10)$ & 30 & $96: 4$ \\
6 & $\mathbf{P 2}(20)^{f}$ & 6 & 38 & $87: 13$ \\
7 & $\mathbf{P 2}(20)^{g}$ & 4 & 61 & $92: 8$ \\
8 & $\mathbf{P 3}(20)^{h}$ & 3 & 84 & $100: 0$ \\
9 & $\mathbf{P 4}(20)^{i}$ & 4 & 57 & $100: 0$ \\
\hline
\end{tabular}

${ }^{a}$ The reactions were performed in EtOH with $10-20 \mathrm{~mol} \%$ of catalyst at room temperature. ${ }^{b}$ Yields of isolated products with purity greater than $95 \%$ according to the ${ }^{1} \mathrm{H}$ NMR analyses. ${ }^{c}$ The ratio of major (2,3-trans-2,4-cis) isomer to minor (2,3-cis-2,4-cis) isomer was determined by the ${ }^{1} \mathrm{H}$ NMR analysis. ${ }^{d}$ The ethyl ester of benzotriazol-5-carboxylic acid (4). ${ }^{e}$ The Wang resin supported benzotriazole with a loading of $0.33 \mathrm{mmol} / \mathrm{g}$ was used. ${ }^{f}$ The MeOPEG-OH supported benzotriazole with a loading of $0.045 \mathrm{mmol} / \mathrm{g}$ was used. ${ }^{g}$ The MeO-PEG-OH supported benzotriazole with a loading of $0.086 \mathrm{mmol} / \mathrm{g}$ was used. ${ }^{h}$ The Merrifield resin supported benzotriazole with a loading of $0.90 \mathrm{mmol} / \mathrm{g}$ was used. ${ }^{i}$ The MeOPEG-OH supported benzotriazole with a loading of $0.15 \mathrm{mmol} / \mathrm{g}$ was used.

(20 mol \%) was used as a promoter, the condensation reaction of $\mathbf{1 c}$ and $\mathbf{2 a}$ in $\mathrm{EtOH}$ solution at $25^{\circ} \mathrm{C}$ gave the 
Table 2. Synthesis of THQs 3a-i in EtOH at $25{ }^{\circ} \mathrm{C}$ Using Merrifield Resin Supported Benzotriazole P3 (20 mol \%) as the Promoter

\begin{tabular}{cccccccc}
\hline entry & arylamine & aldehyde & $\begin{array}{c}\text { reaction } \\
\text { time }(\mathrm{h})^{a}\end{array}$ & products $^{b}$ & $\begin{array}{c}\text { yield } \\
(\%)\end{array}$ & $\begin{array}{c}\text { ratio of } \\
\text { isomers }\end{array}$ & $\begin{array}{c}\text { comparison }^{c} \text { yield } \\
(\text { ratio of isomers) }\end{array}$ \\
\hline 1 & $\mathbf{1 a}$ & $\mathbf{2 a}$ & 16 & $\mathbf{3 a}$ & 84 & $84: 16$ & $86(76: 24)$ \\
2 & $\mathbf{1 b}$ & $\mathbf{2 a}$ & 5 & $\mathbf{3 b}$ & 88 & $82: 18$ & $78(80: 20)$ \\
3 & $\mathbf{1 c}$ & $\mathbf{2 a}$ & 3 & $\mathbf{3 c}$ & 84 & $100: 0$ & $78(95: 5)$ \\
4 & $\mathbf{1 d}$ & $\mathbf{2 a}$ & 24 & $\mathbf{3 d}$ & 88 & $75: 25$ & $80(77: 23)$ \\
5 & $\mathbf{1 e}$ & $\mathbf{2 a}$ & 5.5 & $\mathbf{3 e}$ & 89 & $100: 0$ & $88(100: 0)$ \\
6 & $\mathbf{1 f}$ & $\mathbf{2 a}$ & 6 & $\mathbf{3 f}$ & 88 & $100: 0$ & $68(100: 0)$ \\
7 & $\mathbf{1 g}$ & $\mathbf{2 a}$ & 5 & $\mathbf{3 g}$ & 83 & $100: 0$ & $88(100: 0)$ \\
8 & $\mathbf{2}$ & $\mathbf{2 a}$ & 5 & $\mathbf{3 h}$ & 82 & $100: 0$ & $78(100: 0)$ \\
9 & $\mathbf{1 c}$ & $\mathbf{2 b}$ & 2.5 & $\mathbf{3 i}$ & 87 & $100: 0$ & $85(100: 0)$ \\
\hline
\end{tabular}

${ }^{a}$ The solid-phase synthesis was slower than that using $1 H$-benzotriazole as the promoter. Approximately half of the listed reaction time is required for the corresponding reaction using $1 H$-benzotriazole as the promoter. ${ }^{b}$ The THQ products had a high purity (>95\%) as indicated by HPLC analyses. ${ }^{c}$ The data are adapted from ref 6 for the corresponding reactions using $1 H$-benzotriazole $(20$ mol $\%)$ as the promoter.

desired THQ $3 \mathbf{c}$ in $74 \%$ yield as a mixture of two isomers (2,3-trans-2,4-cis/2,3-cis-2,4-trans $=73: 27)$. The yield and stereoselectivity were somewhat lower than the BtHcatalyzed reaction ${ }^{6}$ (entry 1 in Table 1 ). On the other hand, the reaction promoted by the ether-type benzotriazole 6 (20 mol \%) gave THQ 3c in high yield (90\%) and high stereoselectivity ( $94 \%$ de). Neither $\mathbf{4 a}$ nor $\mathbf{6}$ were recovered for reuse.

When the polymer-bound catalysts P1-P4 (10-20 mol $\%$ ) were used, THQ $3 \mathbf{c}$ was also formed by coupling equal molar amounts of amine 1c and aldehyde $2 \mathbf{a}$ at room temperature in a reasonable period $(3-6 \mathrm{~h})$. The twopair coupling reactions were generally conducted in EtOH. The ether-type benzotriazole $\mathbf{P 3}$ anchored onto Merrifield resin turned out to be the best catalyst to give THQ 3c in $84 \%$ yield as a single isomer with 2,3-trans2,4-cis configuration. By simple filtration, the polymerbound catalyst $\mathbf{P 3}$ was easily recovered and reused with equal efficiency. The reactions using PEG-bound benzotriazoles P2 and P4 afforded only $30-61 \%$ of THQ 3c, not so high-yielding as one might anticipate for a liquidphase synthesis. Using $\mathrm{CH}_{2} \mathrm{Cl}_{2}$ as a cosolvent in the reaction did not improve the yield of 3c. The low yield might be due to low loadings $(\leq 0.15 \mathrm{mmol} / \mathrm{g})$ in $\mathbf{P 2}$ and $\mathbf{P 4}$. The reaction mixture was concentrated and triturated with $\mathrm{Et}_{2} \mathrm{O}$ to give precipitates of $\mathbf{P 2}$ and $\mathbf{P 4}$, which were recovered by filtration.

When Merrifield resin supported benzotriazole P3 (20 mol \%) was used as the promoter, a small library of THQs was established (Table 2). The arylamines included anilines 1a-f, 1-naphthylamine (1g), and 2-fluorenamine (1h). The aldehyde counterparts included phenylacetaldehdye and $o$-bromophenylacetaldehyde (2b). The reactions of anilines 1b, 1c, and 1e containing $\mathrm{C}-3$ substituents $(\mathrm{Me}, \mathrm{OMe}$, or methyleneoxy) occurred exclusively at C-6 rather than C-2 positions presumably because of the steric effect of $\mathrm{C}-3$ substituents. By comparison, the reactions using $\mathrm{BtH}$ as the promoter ${ }^{6}$ were also shown in Table 2. Both the parent $\mathrm{BtH}$ and the polymer-bound benzotriazole $\mathbf{P 3}$ appeared to be effective promoters for the synthesis of THQs. The advantage of using $\mathbf{P 3}$ resided on its facile recovery by simple filtration and ensuring high purity of THQ products.

\section{Experimental Section}

Melting points are uncorrected. ${ }^{1} \mathrm{H}$ NMR spectra were recorded at 300 or $500 \mathrm{MHz} ;{ }^{13} \mathrm{C}$ NMR spectra were recorded at 75 or $100 \mathrm{MHz}$. $\mathrm{CDCl}_{3}\left(\delta_{\mathrm{H}}=7.24\right.$ and $\delta_{\mathrm{C}}=77.0$ (central line of triplet)) was used as an internal standard in ${ }^{1} \mathrm{H}$ and ${ }^{13} \mathrm{C}$ NMR spectra, unless otherwise stated. Mass spectra were recorded at an ionizing voltage of 70 or $20 \mathrm{eV}$. HPLC (Waters, model M-45) analysis was performed on a Lichromsorb Si-60 column using UV detection at $\lambda=254 \mathrm{~nm}$. Merck silica gel 60F sheets were used for analytical thinlayer chromatography. Column chromatography was performed on silica gel (70-230 mesh); gradients of EtOAc and hexane were used as eluents.

THF was distilled from sodium benzophenone ketyl under $\mathrm{N}_{2}$. NaH (60\% dispersed in mineral oil) was washed with anhydrous hexane before use. Wang resin $(0.65 \mathrm{mmol} / \mathrm{g}$, Sigma), Merrifield resin (2\% cross-linked, 2-2.5 mequiv Cl/g, 200-400 mesh, Acros Organics), and monomethoxyPEG-OH (average molecular weight $\sim 5000$, Aldrich) were used. Wang and Merrifield resins were dried under reduced pressure before use. Monomethoxy-PEG-OH was dried by azeotropical removal of water with refluxing acetonitrile.

The isomers of THQ products have been separated by chromatography and fully characterized as reported in ref 6 .

Poly( $\boldsymbol{p}$-alkoxybenzyl)benzotriazole-5-carboxylate (P1). To a solution of benzotriazole-5-carboxylic acid (4) $(0.5 \mathrm{~g}$, $3 \mathrm{mmol}$ ) in $\mathrm{CH}_{2} \mathrm{Cl}_{2}(15 \mathrm{~mL}$ ) was added thionyl chloride ( 0.5 $\mathrm{g}, 4.2 \mathrm{mmol}$ ). After the mixture was stirred at $25^{\circ} \mathrm{C}$ for $5 \mathrm{~h}$, excess $\mathrm{SOCl}_{2}$ was removed under reduced pressure and the resulting solution of acid chloride was added to a mixture of Wang resin $(1.5 \mathrm{~g}, 0.98 \mathrm{mmol})$ and DMAP $(0.1 \mathrm{~g}, 0.09$ $\mathrm{mmol})$. After that, $\mathrm{Et}_{3} \mathrm{~N}(1.1 \mathrm{~mL}, 8 \mathrm{mmol})$ was added, and the mixture was refluxed for $12 \mathrm{~h}$. The resin was filtered, washed successively with water $(10 \mathrm{~mL} \times 2), \mathrm{EtOH}(10 \mathrm{~mL}$ $\times 2)$, and $\mathrm{CH}_{2} \mathrm{Cl}_{2}(10 \mathrm{~mL} \times 2)$. After it was dried, white resin P1 (1.5 g) was obtained. IR (KBr): 1716, 1614, 1362, $1245,1067 \mathrm{~cm}^{-1}$. Elemental analyses (two measurements) showed a nitrogen content of $1.30-1.47 \%$, equivalent to a loading of $0.33 \mathrm{mmol} / \mathrm{g}$ on average.

Methoxy-PEG-OH Benzotriazole-5-carboxylate (P2). An acid chloride was prepared by stirring acid 4 (0.82 g, 5 mmol) with $\mathrm{SOCl}_{2}(5 \mathrm{~mL})$ for $6 \mathrm{~h}$. After removal of excess $\mathrm{SOCl}_{2}$ under reduced pressure, a solution of MeO-PEG- 
$\mathrm{OH}_{5000}(5 \mathrm{~g}, 1 \mathrm{mmol})$ and DMAP (12 mg, $\left.0.1 \mathrm{mmol}\right)$ in $\mathrm{CH}_{2^{-}}$ $\mathrm{Cl}_{2}(25 \mathrm{~mL})$ was added. The mixture was cooled in an ice bath, and $\mathrm{Et}_{3} \mathrm{~N}$ (510 mg, $5 \mathrm{mmol}$ ) was added. After it was stirred for $48 \mathrm{~h}$ at room temperature, the mixture was concentrated to about $5 \mathrm{~mL}$. Triturating with $\mathrm{Et}_{2} \mathrm{O}(35 \mathrm{~mL})$ gave precipitates, which were filtered and washed successively with $\mathrm{Et}_{2} \mathrm{O}(20 \mathrm{~mL})$, 2-propanol $(30 \mathrm{~mL})$, EtOAc/ hexane $(1: 9,30 \mathrm{~mL})$, and $\mathrm{Et}_{2} \mathrm{O}(20 \mathrm{~mL})$. After they were dried, white powders of $\mathbf{P 2}$ (4.89 g) were obtained. IR (KBr): 3453, 2889, 1722, 1469, 1282, $1114 \mathrm{~cm}^{-1} .{ }^{1} \mathrm{H}$ NMR $\left(400 \mathrm{MHz}, \mathrm{DMSO}-d_{6}\right): \delta 8.53(1 \mathrm{H}, \mathrm{s}), 7.94(2 \mathrm{H}, \mathrm{s}), 4.56$ $\left(2 \mathrm{H}\right.$, br s, $\left.\mathrm{BtCO}_{2} \mathrm{CH}_{2}\right), 4.21\left(2 \mathrm{H}\right.$, br s, $\left.\mathrm{MeOCH}_{2}\right)$. Elemental analyses (four measurements) showed a nitrogen content of $0.32-0.44 \%$, equivalent to a loading of $0.086 \mathrm{mmol} / \mathrm{g}$ on average.

Another preparation using 4 and $\mathrm{MeO}-\mathrm{PEG}-\mathrm{OH}_{5000}$ in a molar ratio of 1.5:1 gave $\mathbf{P 2}$ with a loading of $0.045 \mathrm{mmol} / \mathrm{g}$ (on an average of $0.31-0.52 \%$ nitrogen content from four measurements).

5-[(Polystyrene-bound)methoxymethyl]benzotriazole (P3) ${ }^{8 c}$ According to the known procedure, ${ }^{8 c}$ linkage of the sodium salt of 5 (1.95 g, $5 \mathrm{mmol})$ with Merrifield resin ( $2 \mathrm{~g}, 4-5 \mathrm{mmol}$ ), followed by removal of the trityl group with concentrated $\mathrm{HCl}$, gave resin $\mathbf{P 3}$ (2.18 g). Elemental analyses (including two measurements of $\mathbf{P 3}$ and two measurements of its trityl precursor) showed a nitrogen content of 3.49-4.10\%, equivalent to a loading of 0.90 $\mathrm{mmol} / \mathrm{g}$ on average.

5-[(Methoxy-PEG-oxy)methyl]benzotriazole (P4). A suspension of monomethoxy-PEG-OH $\mathrm{OH}_{5000}(1.25 \mathrm{~g})$ was treated with $\mathrm{NaH}(7.5 \mathrm{mg}, 0.3 \mathrm{mmol})$ in anhydrous THF (40 mL) at $25{ }^{\circ} \mathrm{C}$ for $5 \mathrm{~h}$. A solution of $\mathrm{N}$-trityl-5-bromomethylbenzotriazole (7) $(227 \mathrm{mg}, 0.5 \mathrm{mmol})$ and tetrabutylammonium iodide $(12 \mathrm{mg}, 0.03 \mathrm{mmol})$ in THF $(10 \mathrm{~mL})$ was added. The mixture was refluxed for $16 \mathrm{~h}$, and the TLC analysis indicated complete consumption of the bromide 7 . The reaction mixture was cooled, and THF was removed under reduced pressure. To the thick mass was added $\mathrm{Et}_{2} \mathrm{O}$ $(25 \mathrm{~mL})$. The resins were collected by filtration and washed successively with $\mathrm{Et}_{2} \mathrm{O}(10 \mathrm{~mL} \times 3)$ and 2-propanol $(10 \mathrm{~mL}$ $\times 3$ ). White powders of $N$-trityl-5-[(methoxy-PEG-oxy)methyl]benzotriazole $(1.23 \mathrm{~g})$ were obtained after drying as a mixture of $N_{1^{-}}, N_{2^{-}}$and $N_{3}$-trityl isomers according to the ${ }^{1} \mathrm{H}$ NMR analysis.

After they were stirred with concentrated $\mathrm{HCl}(2.5 \mathrm{~mL})$ in $\mathrm{THF} / \mathrm{MeOH}(25 \mathrm{~mL}, \mathrm{v} / \mathrm{v}=3: 2)$ at $25{ }^{\circ} \mathrm{C}$ for $5 \mathrm{~h}$, the powders were collected by filtration, washed successively with $\mathrm{Et}_{2} \mathrm{O}(10 \mathrm{~mL} \times 3)$ and 2-propanol $(10 \mathrm{~mL} \times 3)$, and dried to give $\mathbf{P 4}$ (1.04 g). IR (KBr): 3441, 3009, 2886, 1645, 1470, 1283, 1250, $1110 \mathrm{~cm}^{-1}$. ${ }^{1} \mathrm{H}$ NMR (500 MHz, DMSO$\left.d_{6}\right): \delta 7.90-7.79(2 \mathrm{H}, \mathrm{m}), 7.37(1 \mathrm{H}, \mathrm{s}), 4.63(2 \mathrm{H}, \mathrm{s}$, $\mathrm{BtCH}_{2} \mathrm{O}$ ). Elemental analyses (including two measurements of $\mathbf{P 4}$ and two measurements of its trityl precursor) showed a nitrogen content of $0.61-0.66 \%$, equivalent to a loading of $0.15 \mathrm{mmol} / \mathrm{g}$ on average.

Representative Procedure for the Formation of THQs Using Polymer-Supported Benzotriazoles as Catalysts. 1. Liquid-Phase Synthesis. PEG-bound benzotriazole P2 $(0.92 \mathrm{~g}, 0.083 \mathrm{mmol})$ was dissolved in hot EtOH $(5 \mathrm{~mL})$ and then cooled to room temperature. A solution of phenylacetaldehyde $(50 \mathrm{mg}, 0.42 \mathrm{mmol})$ in EtOH $(1 \mathrm{~mL})$ was added. After the mixture was stirred for $5 \mathrm{~min}$, a solution of 3-methoxyaniline (56 mg, $0.46 \mathrm{mmol})$ in $\mathrm{EtOH}(1 \mathrm{~mL})$ was added. The mixture was stirred at room temperature for $6 \mathrm{~h}$, while the progress of reaction was monitored by TLC analysis $($ EtOAc/hexane $=3: 7)$. The mixture was concentrated to about $1 \mathrm{~mL}$ and triturated with $\mathrm{Et}_{2} \mathrm{O}(10-15 \mathrm{~mL})$ to give precipitates. After the mixture was cooled in an ice bath, the solids were filtered and washed successively with $\mathrm{Et}_{2} \mathrm{O}$ (15 mL), 2-propanol (15 mL), EtOAc/hexane (1:9, 15 $\mathrm{mL})$, and $\mathrm{Et}_{2} \mathrm{O}(10 \mathrm{~mL})$ to give $\mathbf{P 2}(>97 \%$ recovery). The filtrate was concentrated and chromatographed on a silica gel column by elution with EtOAc/hexane (1:9) to give THQ product 3c [59\% yield of 2,3-trans-2,4-cis isomer $(56 \mathrm{mg})$ and $2 \%$ yield of 2,3-cis-2,4-cis isomer $(5 \mathrm{mg})]$. The recovered P2 catalyst was reused for the other two cycles to give similar results.

2. Solid-Phase Synthesis. A mixture of 3-methoxyaniline (1c, $123 \mathrm{mg}, 1 \mathrm{mmol}$ ), phenylacetaldehyde (2a, $120 \mathrm{mg}, 1$ $\mathrm{mmol}$ ), and polymer-bound benzotriazole $\mathbf{P 3}$ (196 mg, 0.20 mmol) in EtOH solution $(2 \mathrm{~mL})$ was stirred at room temperature $\left(25^{\circ} \mathrm{C}\right)$ for $3 \mathrm{~h}$. The resins were filtered and washed successively with EtOH $(5 \mathrm{~mL} \times 2), \mathrm{CH}_{2} \mathrm{Cl}_{2}(5 \mathrm{~mL}$ $\times 2)$, and $\mathrm{Et}_{2} \mathrm{O}(5 \mathrm{~mL} \times 2)$. The filtrate was concentrated to give THQ product $3 \mathbf{c}$ (205 $\mathrm{mg}, 84 \%$ yield) with the 2,3trans-2,4-cis configuration. Resin P3 (194 mg, 99\% recovery) was recovered and reused to give similar results.

Acknowledgment. We thank the National Science Council for financial support.

\section{References and Notes}

(1) For recent monographs and reviews on combinatorial synthesis, see the following. (a) Thompson, L. A.; Ellman, J. A. Chem. Rev. 1996, 96, 555. (b) Amstrong, R. W.; Combs, A. P.; Tempest, P. A.; Brown, S. D.; Keating, T. A. Acc. Chem. Res. 1996, 29, 123. (c) Gordon, E. M.; Gallop, M. A.; Patel, D. V. Acc. Chem. Res. 1996, 29, 144. (d) Balkenhohl, F.; von dem Bussche-Huennefeld, C.; Lansky, A.; Zechel, C. Angew. Chem., Int. Ed. Engl. 1996, 35, 2289. (e) Wilson, S. R., Czarnik, A. W., Eds. Combinatorial Chemistry, Synthesis and Application; Wiley: New York, 1997. (f) Obrecht, D.; Villalgordo, J. M. In SolidSupported Combinatorial and Parallel Synthesis of SmallMolecular-Weight Compound Libraries; Baldwin, J. E., Williams, R. M., Eds.; Elsevier Science: Oxford, U.K., 1998. (g) Booth, R. J.; Hodges, J. C. Acc. Chem. Res. 1999, 32, 18. (h) Franzen, R. G. J. Comb. Chem. 2000, 2, 195.

(2) For recent monographs and reviews on polymer-supported reagents and catalysts, see the following. (a) Panster, P.; Wieland, S. In Applied Homogeneous Catalysis with Organometallic Compounds, Eds.; Cornils, B., Herrmann, W. A., Eds.; VCH: Weinheim, Germany, 1996; Vol. 2, pp 605623. (b) Shuttleworth, S. J.; Allin, S. M.; Sharma, P. K. Synthesis 1997, 1217. (c) Bolm, C.; Gerlach, A. Eur. J. Org. Chem. 1998, 21. (d) Arshady, R. Microspheres, Microcapsules Liposomes 1999, 1, 197. (e) Kobayashi, S. Top. Organomet. Chem. 1999, 2, 285. (f) Bhattacharyya, S. Comb. Chem. High Throughput Screening 2000, 3, 65. (g) Saluzzo, C.; ter Halle, R.; Touchard, F.; Fache, F.; Schulz, E.; Lemaire, M. J. Organomet. Chem. 2000, 603, 30. 
(3) (a) Leeson, P. D.; Carling, R. W.; Moore, K. W.; Moseley, A. M.; Smith, J. D.; Stevenson, G.; Chan, T.; Baker, R.; Foster, A. C.; Grimwood, S.; Kemp, J. A.; Marshall, G. R.; Hoogsteen, K. J. Med. Chem. 1992, 35, 1954. (b) Katritzky, A. R.; Rachwal, S.; Rachwal, B. Tetrahedron 1996, 52, 15031.

(4) For representative examples of THQ synthesis, see the following. (a) Narasaka, K.; Shibata, T. Heterocycles 1993 35, 1039. (b) Kobayashi, S.; Ishitani, H.; Nagayama, S. Chem. Lett. 1995, 423. (c) Ishitani, H.; Kobayashi, S. Tetrahedron Lett. 1996, 37, 7357. (d) Annunziata, R.; Cinquini, M.; Cozzi, F.; Molteni, V.; Schupp, O. Tetrahedron 1997, 53, 9715. (e) Babu, G.; Perumal, P. T. Tetrahedron Lett. 1998, 39, 3225. (f) Baudelle, R.; Melnyk, P.; Deprez, B.; Tartar, A. Tetrahedron 1998, 54, 4125. (g) Hadden, M.; Stevenson, P. J. Tetrahedron Lett. 1999, 40, 1215. (h) Batey, R. A.; Simoncic, P. D.; Lin, D.; Smyj, P.; Lough, A. J. Chem. Commun. 1999, 651. (i) Ma, Y.; Qian, C.; Xie, M.; Sun. J. J. Org. Chem. 1999, 64, 6462.

(5) (a) Kiselyov, A. S.; Armstrong, R. W. Tetrahedron Lett. 1997, 38, 6163. (b) Kiselyov, A. S.; Smith, L., II; Armstrong, R. W. Tetrahedron 1998, 54, 5089. (c) Kiselyov, A. S.; Smith, L., II; Virgilio, A.; Armstrong, R. W. Tetrahedron 1998, 54, 7987. (d) Kobayashi, S.; Nagayama, S. J. Am. Chem. Soc. 1996, 118, 8977.
(6) Talukdar, S.; Chen, C.-T.; Fang, J.-M. J. Org. Chem. 2000 , 65, 3148.

(7) For a review of the chemistry of benzotriazole, see the following. (a) Katritzky, A. R.; Rachwal, S.; Hitchings, G. J. Tetrahedron 1991, 47, 2683. (b) Katritzky, A. R.; Belyakov, S. A. Aldrichimica Acta 1998, 31, 35. (c) Katritzky, A. R.; Lan, X.; Yang, J. Z.; Denisko, O. V. Chem. Rev. 1998, 98, 409. (d) Katritzky, A. R. J. Heterocycl. Chem. 1999, 36, 1501.

(8) (a) Katritzky, A. R.; Belyakov, S. A.; Tymoshenko, D. O. J. Comb. Chem. 1999, 1, 173. (b) Paio, A.; Zaramella, A.; Ferritto, R.; Conti, N.; Marchioro, C.; Seneci, P. J. Comb. Chem. 1999, 1, 317. (c) Schiemann, K.; Showalter, H. D. H. J. Org. Chem. 1999, 64, 4972. (d) Blaney, P.; Grigg, R.; Rankovic, Z.; Thoroughgood, M. Tetrahedron Lett. 2000, 41,6639 .

(9) (a) Wentworth, P., Jr.; Janda, K. D. Chem. Commun. 1999, 1917. (b) Wentworth, P. Trends Biotechnol. 1999, 17, 448. (c) Sun, C.-M. Comb. Chem. High Throughput Screening 1999, 2, 299. (d) Toy, P. H.; Janda, K. D. Acc. Chem. Res. 2000, 33, 546

CC010010B 